\title{
Surgical Clinical Trials in India: Underutilized Opportunities
}

\author{
Sanjay Kumar Yadav ${ }^{1}\left[\right.$ ] Pawan Agarwal ${ }^{1}\left[\right.$ ] . Dhananjaya Sharma ${ }^{1}[$
}

Received: 27 May 2021 / Accepted: 24 June 2021 /Published online: 30 June 2021

(c) Association of Surgeons of India 2021

\begin{abstract}
Clinical trials in Surgery are central to research; however, very few surgical clinical trials are conducted in India. Such paucity of surgical trials is a cause for concern, and prompted us to explore the recent landscape of surgical trials in India. We reviewed all clinical trials from general surgery or subspecialties of general surgery registered with the Clinical Trials Registry of India website between 2018 to 15 th May 2021. Specific details such as the surgical subspecialty, study design, multicentric or single institution and funding were obtained. We found a total of 16,710 trials, out of these 4119 (24.6\%) were related to all surgical fields. Only $136(0.8 \%)$ trials were found from general surgery and its subspecialties. Most trials were registered from Central Government Institutions (48\%), followed by State Government Medical Colleges (11\%). Most number of trials was registered from GI surgery (32\%). Most (90.5\%) trials were single centre based. Common barriers to research are well known; if the State Government Medical Colleges can mentor a culture of research from an early stage of surgical training it can improve research productivity. Multicentre trials, involving smaller hospitals from tier 2 and tier 3 cities, are a potential solution to one of the major obstacles of surgical trials i.e. small number of patients; especially in this pandemic induced draught of elective surgical operations. A positive change in attitude of surgeons and provision of necessary funding can encourage more surgical clinical trials in India.
\end{abstract}

Keywords Surgery $\cdot$ Clinical trials $\cdot$ Surgical subspecialties $\cdot$ Barriers to research $\cdot$ Multicentre trials

\section{Introduction}

A clinical trial is conducted with the aim of determining safety and efficacy of new therapies, or diagnostic procedures, or new ways of using known treatments. Logically, a well-conducted randomized control trial (RCT) is considered as the best form of evidence due to its various advantages. [1] Many surgical RCTs and observational trials have taken place over the last few decades, across the spectrum of all surgical specialties, and have influenced various positive changes in surgical practice. However, majority of these have originated from developed countries. Thiagarajan et al. in their landmark study explored the Clinical Trials Registry

Dhananjaya Sharma

dhanshar@gmail.com

Sanjay Kumar Yadav

sky1508@gmail.com

Pawan Agarwal

drpawanagarwal@yahoo.com

1 Department of Surgery, NSCB Government Medical

College, Jabalpur, MP 482003, India of India (CTRI) for number of surgical trials registered from July 2007 to April 2018 and found only 373 (2.8\%) surgical trials among 13,301 registered in the study period [2]. Such paucity of surgical trials is a cause for concern and prompted us to explore the recent landscape of surgical trials in India.

\section{Methods}

We conducted a review of clinical trials registered with the CTRI website [3]. All the trials registered between 2018 and 15 May 2021 were analysed with predefined inclusion criteria.

\section{Inclusion Criteria:}

1. Surgical trials from general surgery or subspecialties of general surgery

2. Trial done to assess and/or compare distinct surgical procedures or devices, surgical techniques, and addition of another treatment modality to surgery 
3. Surgical trial where principal investigator (PI) is from general surgical discipline or its subspecialties

\section{Exclusion Criteria:}

1. Surgical trials from other surgical specialties such as gynaecology, ophthalmology, orthopaedics, and otorhinolaryngology

2. Surgical trials where PI is not from general surgery or its subspecialties such from anaesthesia or medical oncology

Specific details about the trials such as the year of registration, surgical subspecialty, study design, multicentric or single institution, and funding were obtained. For surgical oncology, there was significant overlap with other subspecialties; for example, gastrointestinal surgery (GI) divisions had many GI cancers. Hence, these trials were included in core subspecialties, and other surgical oncology trials not belonging to a core subspecialty, such as breast cancer or peripheral soft tissue sarcoma, were included in oncosurgery.
The trend of surgical trials registered over this period was also noted. Data was analysed using Microsoft excel.

\section{Results}

Our search of CTRI database found a total of 16,710 trials registered from January 2018 to 15 May 2021. Out of these, 4119 (24.6\%) were related to surgical field. After excluding trials registered from other surgical specialities such as gynaecology, orthopaedics, otorhinolaryngology, ophthalmology, anaesthesia, or other specialties, only $136(0.8 \%)$ trials were found to be eligible for analysis under general surgery and its subspecialties based on our definition. The number of RCTs registered increased slightly from 2018 to 2019 but nose-dived from 2020 onwards, coinciding with COVID-19 pandemic (Table 1). Most trials were registered from central government institutions (48\%) followed by state government medical colleges (11\%) and private sector institutes $(11 \%)$. Incidence of observational and interventional trials was almost equal, $47 \%$ and $53 \%$, respectively. When analysed by specialty, most number of trials were registered
Table 1 Summary of surgical trials registered in India from 1 January 2018 to 15 May 2021

\begin{tabular}{|c|c|c|}
\hline & & $\mathrm{N}(\%)$ \\
\hline Year & $\begin{array}{l}2018 \\
2019 \\
2020 \\
2021 \text { (Up to May } 15)\end{array}$ & $\begin{array}{l}52 \\
59 \\
17 \\
8\end{array}$ \\
\hline Type of institution & $\begin{array}{l}\text { 1. Central government institutes } \\
\text { 2. State government institutes } \\
\text { 3. State government medical colleges } \\
\text { 4. Private sector institutes } \\
\text { 5. Public sector hospitals } \\
\text { 6. Private sector hospitals }\end{array}$ & $\begin{array}{l}65(48.0) \\
13(9.5) \\
15(11.0) \\
15(11.0) \\
4(3.0) \\
11(8.0)\end{array}$ \\
\hline Type of study & $\begin{array}{l}\text { 1. Observational } \\
\text { 2. Interventional }\end{array}$ & $\begin{array}{l}64(47.0) \\
72(53.0)\end{array}$ \\
\hline Surgical specialty & $\begin{array}{l}\text { 1. General Surgery } \\
\text { 2. Gastrointestinal surgery } \\
\text { 3. Neurosurgery } \\
\text { 4. Plastic surgery } \\
\text { 5. Paediatric surgery } \\
\text { 6. Endocrine surgery } \\
\text { 7. Cardiovascular and thoracic surgery } \\
\text { 8. Urology } \\
\text { 9. General oncosurgery (breast, soft tissue } \\
\text { sarcoma, etc.) } \\
\text { * Oncosurgery (total) }\end{array}$ & $\begin{array}{l}13(9.5) \\
44(32.0) \\
17(12.5) \\
5(3.6) \\
6(4.4) \\
6(4.4) \\
18(13) \\
17(12.5) \\
9(6.6) \\
48(35.0)\end{array}$ \\
\hline Centres & $\begin{array}{l}\text { 1. Single centre } \\
\text { 2. Multi centre }\end{array}$ & $\begin{array}{l}123(90.5) \\
13(9.5) \\
\text { [CTVS-2, Neurosurgery-2, } \\
\text { General surgery-4, Oncosur- } \\
\text { gery-5] }\end{array}$ \\
\hline Funding & $\begin{array}{l}\text { 1. Intramural funding } \\
\text { 2. Extramural funding } \\
\text { 3. Non funded }\end{array}$ & $\begin{array}{l}95(70 \%) \\
24(17.6 \%) \\
11(8 \%)\end{array}$ \\
\hline
\end{tabular}

Asterix was placed to show that Oncosurgery had the largest number of registered trials 
from GI surgery (32\%), followed by cardio-thoracic and vascular surgery $(13 \%)$, neurosurgery $(12.5 \%)$, and urology $(12.5 \%)$. Overall, $35 \%$ trials were registered for oncological diseases. Most (90.5\%) trials were single centre based; commonest multicentric trials were for oncosurgery $(n=5)$. Most (70\%) trials were funded by the institutes conducting the study (Table 1). Geographical locations of centres in India conducting these surgical trials are shown in Fig. 1.

\section{Discussion}

Well-designed, well-analysed, and well-reported clinical trials play the central role in surgical research. Happily, surgical research has come a long way from the days when publications of case series were its commonest form, leading to the infamous taunt of comparing surgical research to comic opera [4]. Realizing the need of the hour and perhaps spurred by such disdainful comments, the volume of published surgical RCTs has been increasing steadily, although Indian authors published only 4\% (19/450) of all surgical RCTs in 2009 [5]. Few landmark surgical RCTs have been published from India, though their numbers are small [6-13]. Our study confirms the meagre proportion of surgical clinical trials in India ( $0.8 \%$ of all clinical trials for the study period), as was seen in the previous study on this issue [2]. They had found 2.8\% surgical trials (including all branches of surgery such as gynaecology, orthopaedics, otorhinolaryngology, ophthalmology, or other specialties) among 13,301 trials registered in the study period from 2007 to April 2018; oncology-related surgical trials were $10 \%$; and most surgical trials were in surgical gastroenterology (19.8\%) [2]. Such specialty-wise data is also similar to our findings.

Notwithstanding such paucity of surgical trials, realistically, clinical trials in surgery are not as easy to perform as in medicine. This is due to inherent complexities associated with surgical procedures such as the learning curve associated with surgical techniques, difference in surgical skills of different surgeons, standardization of surgical procedures, different presentations of disease, differences in anaesthesia and peri-operative care of patients in different settings, patients' reluctance towards recruitment for any invasive procedure, and inclusion bias and difficulty with blinding [14]. These difficulties can be overcome with surgically "flavoured" solutions, and necessary surgical trials, though difficult, can be performed for generating evidence on which to base surgical practice $[15,16]$.
Fig. 1 Map of India showing centres from cities which have registered surgical trials on CTRI website (2018-2021)

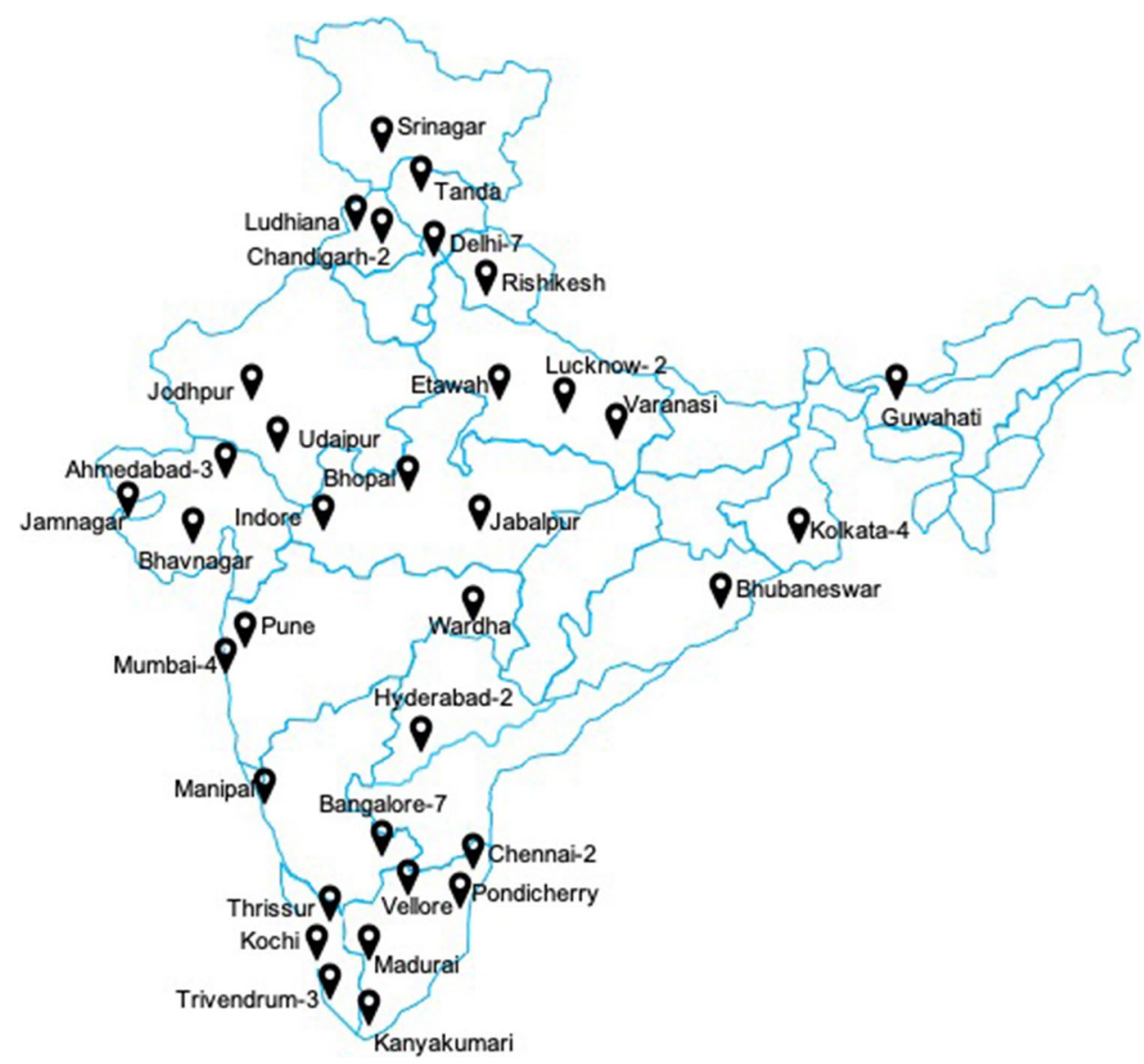


Our study also highlights a couple of interesting facts about this type of surgical research in India. Only a handful (15 out of 136) of trials was registered from the state government medical colleges. Common barriers to research are well known and include lack of motivation, lack of resources, lack of data, lack of research methodology training, insufficient dedicated research time, and lack of funding and rewards [17-19]. It is equally well-known that the culture of research and publication must be inculcated from an early stage of surgical training as early exposure has a strong positive influence on later involvement in research [20, 21]. Here lies the importance of mentorship programmes to improve research productivity among younger colleagues [22]. Now when the rewards of research and bringing research funding are reflected in academic promotions, it is self-evident that these solutions are part of the job description of the teachers in the state government medical colleges.

The other interesting finding of our study is that less than $10 \%$ of registered surgical trials in India are multicentric. Multicentre trials are a potential solution to one of the major obstacles of surgical trials, i.e. small number of patients. In this ongoing COVID-19 pandemic, when most of the clinical work has been reduced to only essential services in majority of surgical units, the role of multicentric studies cannot be over emphasized. Availability of broadband Internet connections and ease of online collaborations have brought the feasibility of multicentric trials to everyone's doorstep [23]. An additional advantage of this is the possibility of increasing participation by smaller hospitals from tier 2 and tier 3 cities. Medical colleges should focus on day to day challenges, own experiences, and available resources to select a trial topic rather than duplicating something already published. Another important aspect is strengthening of medical records keeping in state medical colleges and upgrading to digitized format. With 1.4 billion population, India is home to a growing population requiring surgical care. Number of surgeries performed at hospitals in tier two and three cities are many folds higher than national Institutes. However, most research is conducted in central institutes and needs longer time to complete due to poor patient accrual. This is the major underutilized opportunity that despite having large number of patients, we are not able to enrol them in surgical trials. Collaboration is the most under-sold aspect of clinical research in India. Being able to work with and learn from experts of other institutes can enhance the quality and quantity of surgical research in India.

A possible limitation of our study is that a few centres may not be registering their trials and many trials registered may not be underway due to poor accrual of patients or lack of funding. However, scarcity of surgical trials from India is quite evident, and miniscule contribution of Indian authors in scientific surgical journals is an additional cause for concern [17]. Barriers to both are common as are the solutions.
A positive change in attitude of surgeons and provision of necessary funding will go a long way to mitigate these problems. Equal importance must be given to patient-related factors and proper scientific reporting of surgical clinical trials $[24,25]$. Now, when the roadmap is available for clinically relevant research and publications even in resourceconstrained conditions [26], all stakeholders must come on board of the surgical research bandwagon to put India among the frontiers of surgical research. A treasure trove of surgical clinical trials beckons valiant treasure seekers.

\section{Declarations}

Conflict of Interest/Competing Interests The authors declare no competing interests.

\section{References}

1. Kumar S (2019) Evidence in surgery-levels and significance. Indian J Surg 81:307-316. https://doi.org/10.1007/ s12262-019-01939-8

2. Thiagarajan S, Fatehi K, Pramesh CS (2020) Clinical trials in surgical specialties in india-an analysis and interpretation of trials registry data. Indian J Surg 82:1081-1087. https://doi.org/10. 1007/s12262-020-02230-x

3. Clinical Trials Registry - India (CTRI). Available at www.ctri.nic. in. Accessed 15 May 2021

4. Horton R (1996) Surgical research or comic opera: questions, but few answers. Lancet 347(9007):984-985. https://doi.org/10.1016/ s0140-6736(96)90137-3

5. Ahmed Ali U, van der Sluis PC, Issa Y, Habaga IA, Gooszen HG, Flum DR, Algra A, Besselink MG (2013) Trends in worldwide volume and methodological quality of surgical randomized controlled trials. Ann Surg 258(2):199-207. https://doi.org/10.1097/ SLA.0b013e31829c7795

6. Kate V, Ananthakrishnan N, Badrinath S (2001) Effect of Helicobacter pylori eradication on the ulcer recurrence rate after simple closure of perforated duodenal ulcer: retrospective and prospective randomized controlled studies. Br J Surg 88(8):1054-1058. https://doi.org/10.1046/j.0007-1323.2001.01831.x

7. Bikhchandani J, Agarwal PN, Kant R, Malik VK (2005) Randomized controlled trial to compare the early and mid-term results of stapled versus open hemorrhoidectomy. Am J Surg 189(1):5660. https://doi.org/10.1016/j.amjsurg.2004.03.014

8. Garg P, Nair S, Shereef M, Thakur JD, Nain N, Menon GR, Ismail M (2011) Mesh fixation compared to nonfixation in total extraperitoneal inguinal hernia repair: a randomized controlled trial in a rural center in India. Surg Endosc 25(10):3300-3306. https:// doi.org/10.1007/s00464-011-1708-z

9. Kumar S, Rai R, Agarwal GG, Dwivedi V, Kumar S, Das V (2013) A randomised double blind placebo controlled clinical trial of Centchroman (Ormeloxifene) in breast pain and nodularity (benign breast disorder). Natl Med J India 26:69-74

10. Badwe R, Hawaldar R, Nair N, Kaushik R, Parmar V, Siddique S, Budrukkar A, Mittra I, Gupta S (2015) Locoregional treatment versus no treatment of the primary tumour in metastatic breast cancer: an open-label randomised controlled trial. Lancet Oncol 16(13):1380-1388. https://doi.org/10.1016/S1470-2045(15) 00135-7 
11. Palanivelu C, Senthilnathan P, Sabnis SC, Babu NS, SrivatsanGurumurthy S, AnandVijai N, Nalankilli VP, Praveen Raj P, Parthasarathy R, Rajapandian S (2017) Randomized clinical trial of laparoscopic versus open pancreatoduodenectomy for periampullary tumours. Br J Surg 104(11):1443-1450. https://doi.org/10. 1002/bjs. 10662

12 Sundaramurthy S, Joseph Thomas R, Herle K, Jeyaseelan Mathai J, Jacob Kurian J (2019) Double J stent removal in paediatric patients by vellore catheter snare technique: a randomised control trial. J Pediatr Urol 15(6):661.e1-661.e8. https://doi.org/10.1016/j. jpurol.2019.08.009

13 Bajaj J, Doddamani R, Chandra SP, Ratre S, Parihar V, Yadav Y, Sharma D (2021) Comparison of peripheral neurectomy vs. medical treatment for migraine: a randomized controlled trial. Neurol India 69(Supplement):S110-S115. https://doi.org/10.4103/00283886.315973

14. Solheim O (2019) Randomized controlled trials in surgery and the glass ceiling effect. Acta Neurochir (Wien) 161(4):623-625. https://doi.org/10.1007/s00701-019-03850-3

15. Ergina PL, Cook JA, Blazeby JM, Boutron I, Clavien PA, Reeves $\mathrm{BC}$ et al (2009) Challenges in evaluating surgical innovation. Lancet 374(9695):1097-1104. https://doi.org/10.1016/S01406736(09)61086-2

16. (2009) Surgical research: the reality and the IDEAL. Lancet. 374(9695):1037. https://doi.org/10.1016/S0140-6736(09)61678-0.

17. Reddy CM, Paramashivaiah N, Reddy HVR, Lakshman K (2020) An Audit of General Surgery Publications by Indian Authors. Indian J Surg 82:1-5. https://doi.org/10.1007/s12262-020-02514-2

18. Conradie A, Duys R, Forget P, Biccard BM (2018) Barriers to clinical research in Africa: a quantitative and qualitative survey of clinical researchers in 27 African countries. Br J Anaesth 121(4):813-821. https://doi.org/10.1016/j.bja.2018.06.013

19 Al-Judaibi B, Dokus MK (2021) Barriers to research productivity among physicians in Saudi Arabia: taking a deep dive into the world of academia. Saudi J Gastroenterol. 27(2):61-63. https:// doi.org/10.4103/sjg.sjg_7_21
20. Lloyd T, Phillips BR, Aber RC (2004) Factors that influence doctors' participation in clinical research. Med Educ 38(8):848-851. https://doi.org/10.1111/j.1365-2929.2004.01895.x

21. Boyle SE, Cotton SC, Myint PK, Hold GL (2017) The influence of early research experience in medical school on the decision to intercalate and future career in clinical academia: a questionnaire study. BMC Med Educ 17(1):245. https://doi.org/10.1186/ s12909-017-1066-1

22. Cho CS, Ramanan RA, Feldman MD (2011) Defining the ideal qualities of mentorship: a qualitative analysis of the characteristics of outstanding mentors. Am J Med 124(5):453-458. https://doi. org/10.1016/j.amjmed.2010.12.007

23. NIHR Global Health Research Unit on Global Surgery (2021) Pragmatic multicentre factorial randomized controlled trial testing measures to reduce surgical site infection in low- and middleincome countries: study protocol of the FALCON trial. Colorectal Dis 23(1):298-306. https://doi.org/10.1111/codi.15354

24. Shah JY, Phadtare A, Rajgor D, Vaghasia M, Pradhan S, Zelko H, Pietrobon R (2010) What leads Indians to participate in clinical trials? A meta-analysis of qualitative studies. PLoS ONE 5(5):e10730. https://doi.org/10.1371/journal.pone.0010730

25. Yu J, Li X, Li Y, Sun X (2017) Quality of reporting in surgical randomized clinical trials. Br J Surg 104(3):296-303. https://doi. org/10.1002/bjs. 10331

26. Sharma D, Agrawal V, Agarwal P (2021) Editorial: roadmap for clinical research in resource-constrained settings. Trop Doct 51(1):4-5. https://doi.org/10.1177/0049475520974844

Publisher's Note Springer Nature remains neutral with regard to jurisdictional claims in published maps and institutional affiliations. 